\title{
"You have a status": a case study of parent leadership in a U.S. school readiness initiative
}

\author{
Anne L. Douglass ${ }^{1 *} \mathbb{D}$, Meredith R. Maroney ${ }^{1}$, Mary Coonan², Donna Haig Friedman² and Alice Carter ${ }^{3}$
}

\author{
${ }^{*}$ Correspondence: \\ Anne.Douglass@umb.edu \\ ${ }^{1}$ College of Education \\ and Human Development, \\ University of Massachusetts \\ Boston, 100 Morrissey Blvd., \\ Boston, MA 02125, USA \\ Full list of author information \\ is available at the end of the \\ article
}

\begin{abstract}
This study examined an urban school readiness initiative that developed parent leadership as a key strategy for increasing the likelihood that all children enter kindergarten ready to succeed. Parent Leaders were primarily immigrant mothers who conducted outreach activities and child developmental screenings with low income, under-served, urban and immigrant families with young children. Using a rigorous case study design, this qualitative study investigated what strategies Parent Leaders used to engage families and how their leadership influenced families, neighborhoods, and the Parent Leaders themselves. The study found that Parent Leaders (1) used highly relational strategies to engage families, (2) shifted community norms about parent leadership, and (3) developed their own identities as leaders. These findings contribute to an increased understanding of how and why parent leadership matters for school readiness research, practice, and policy, particularly in immigrant and under-served communities.
\end{abstract}

This study examined parent leadership in an urban school readiness initiative in a northeast U.S. city. This school readiness initiative (hereafter referred to as Ready for K) took a unique approach by mobilizing parent leadership as one key strategy toward meeting its goal that every child in the city would enter kindergarten ready to succeed. Ready for $\mathrm{K}$ determined that parents in under-resourced neighborhoods could be the most effective "ambassadors" conducting outreach and engagement, and leading the efforts to connect families to early learning and developmental supports. Their approach was based on the idea that effective connections of families to resources, supports, and services are vital to children's developmental growth, yet these connections needed to be enhanced for subgroups of families with young children, particularly low-resourced, immigrant families who are the least connected to services and resources.

Ready for $\mathrm{K}$ pursued a strategy of mobilizing local parent leadership to strengthen families' connections with school readiness support systems. It recruited community parents to conduct outreach to underserved and immigrant parents of young children to connect them with local resources. It also trained these parents to conduct developmental screenings of children birth to age three to raise family and community awareness about children's development and, when appropriate, early intervention services. Few early childhood school readiness or developmental screening initiatives involve parents as the implementers and leaders. Moreover, little research has examined parent 
leadership as a strategy for promoting early learning or school readiness. Therefore, this paper offers an innovative and useful contribution.

This qualitative case study of Ready to K investigated (1) the strategies Parent Leaders used in their efforts to engage families and (2) how the development of parent leadership influenced families, neighborhoods, and the Parent Leaders themselves. We begin with a review of the literature on parent leadership in the early childhood education context. Next, we describe the context for this study and the research methods. We present the key research findings and discuss our findings in relation to implications for future research, policy, and practice.

\section{Literature review}

Improving parent engagement has garnered attention as a way to achieve more equitable access to quality early care and education (ECE) and school readiness opportunities (Hepburn 2004; Park and McHugh 2014; Souto-Manning and Swick 2006). There is strong evidence that parent engagement in education during the early childhood years contributes to positive child outcomes and academic achievement, and parent engagement is considered as a key strategy for closing the achievement gap (Henderson et al. 2004; Hepburn 2004; Vlasov and Hujala 2017). This literature explores various approaches to and/or benefits of parent involvement, and how parent engagement might influence children's academic learning (Hakyemez-Paul et al. 2018; Morrow and Malin 2004; Park and McHugh 2014). Research across international contexts notes the importance of parent engagement and parent-teacher partnerships as a core element of quality ECE and one that merits further attention in both research and practice (OECD 2012, 2017; Vlasov and Hujala 2017; Douglass 2011; Douglass and Klerman 2012).

The parent engagement literature also considers how parent involvement may shift as a result of a range of contextual factors. For example, Vlasov and Hujula (2017) examined the evolution of parent-teacher relationships in ECE over time in Russia, the US, and Finland. They describe societal changes that may influence how parents are positioned in relation to teachers with regards to power and status, as well as differences in these power dynamics across the three country contexts in their study. This and other research identify power relations between parents and teachers as a key issue for parent engagement research and practice (Douglass 2011). The parent leadership literature addresses these issues of power, status, and empowerment.

\section{Parent leadership}

Parent leadership is considered as one core dimension of comprehensive parent and family engagement frameworks in the U.S., yet very little research has examined this specific dimension of family engagement or how parent leadership might influence parents' role and empowerment (Cunningham et al. 2012; National Center on Parent, Family and Community Engagement 2019; U.S. Department of Health and Human Services 2011). For example, parent leadership is a central element of Head Start's comprehensive parent and family engagement framework. This framework defines parent leadership in a range of ways, including participation in decision-making, policy development, and organizing activities in communities to improve children's health, safety, development, and/or learning experiences. However, little guidance or research evidence is available 
about how to development, support, sustain, and measure outcomes of parent leadership in ECE programs and systems (U.S. Department of Health and Human Services 2011).

Parent leadership, particularly in the context of ECE and school readiness, and its impact on communities as well as on child outcomes, has received little attention in the ECE research literature. The existing research on parent leadership comes primarily from other disciplines, specifically family support and K-12 education, rather than from ECE (Bolívar and Chrispeels 2011; Hepburn 2004). The family support approach to parent leadership recognizes the value of supporting natural leaders in communities to be change agents (Langford and Weissbourd 1997; Toso and Gungor 2012). In the education literature, parent leadership has been described as advocating for change on behalf of one's own child or a community, participating in educational councils or parent boards, recruiting new parents to become engaged, participating in education reform and community organizing, and authentic input in decision-making (Cunningham et al. 2012). In Ready for K, Parent Leaders engaged families in their neighborhoods to connect them with local early learning resources such as play groups, public library story times, and family support organizations. They also conducted developmental screenings of young children with their parents and made referrals to early intervention services when appropriate.

\section{Parent leadership development}

How is parent leadership cultivated and developed? Parent leadership development is a concept that has not yet been widely applied in the field of human services, and even less so within early education and school readiness contexts. The limited research in this area and the dearth of robust frameworks or models for effectively promoting leadership development presents challenges (Brittain 2014). Although the research is limited, studies do offer some ideas about key components of parent leadership development, such as the importance of intentional emphasis on diversity, identity, cultural competency, and empowerment (Ball 2008; Blitz and Greene 2014; Brittain 2014; Gutierrez 2013; Park and McHugh 2014; Solloway and Girouard 2004; Swick 2001). Cunningham et al. (2012) found that when parents were provided training that incorporated an empowerment approach, there were both immediate and long-term gains in parents' leadership capacity and activity. Connecting parents with one another to facilitate their mutual learning and to serve as mentors for less experienced parents has been suggested as a way of empowering parents (Swick 2001). Efforts to support parents' identity as leaders may also be important. For example, Walker (2009) examined how the "language of leadership can help shape parents as leaders," in a developmental process toward "intentionally constructing their own social reality as leaders" (p. 80). The importance of developing a leadership identity is supported by research on women's leadership, which may be particularly relevant to this study given that all of the parent leaders in Ready for $\mathrm{K}$ were women (Douglass 2018). Because dominant notions of leadership often conform to societal stereotypes about men, Ely et al. (2011) argue that leadership identity must be the foundation of women's leadership development. They highlight how this identity strengthens women's confidence as leaders: "An elevated sense of purpose challenges leaders to move outside of their comfort zones, shifts their attention from what is to 
what is possible, and gives them a compelling reason to face down their fears and insecurities and take action despite them" (p. 476).

\section{Benefits of parent leadership}

Research points to a wide range of possible positive outcomes of parent leadership, including increased parental self-confidence, increased social capital and civic and school engagement, empowerment, and enhancement of skills leading to employment (Ball 2008; Bray and Kenney 2014; Cunningham et al. 2012). Recent research suggests that when parents are involved with their child's education and view themselves as leaders of their families, their confidence increases, as does their capacity to be effective advocates and parents (Bray and Kenney 2014; Bray et al. 2014; Gutierrez 2013). Bolívar and Chrispeels (2011) found that "when parents participate in leadership development, they are empowered to effect changes that benefit their children through individual and collective actions" (p. 4). These findings suggest a range of potential positive impacts of parent leadership programs.

Parent leadership development may also influence educators, and the way they view and interact with parents. Geller and colleagues (2015) studied a parent leadership effort and found that increasing interactions that promote trust and respect between parents and teachers may reduce the deficit-based perspectives held by many educators, such as the belief that parents are not capable of being good parents (Geller et al. 2015). They suggest that training teachers about parent engagement is, by itself, an insufficient strategy to promote effective parent-teacher partnerships, and they argue that parent leadership development is an important and complementary strategy. They propose a dual-capacity building approach that includes both educator professional development and parent leadership development.

In summary, the literature suggests that (1) parent leadership is an important but often neglected element of parent engagement, and (2) parent leadership development may offer a wide range of potential benefits that can positively influence the parents themselves, as well as children, families, community professionals, and neighborhoods. The limited research on parent leadership development highlights a gap in our understanding of how parent leadership might matter, and what outcomes are possible from investing in this approach. There is still much to be learned about how to conceptualize and effectively facilitate the development of parent leaders within ECE contexts. This study seeks to examine several of the areas in which there are gaps in the ECE parent leadership literature, such as what parent leaders do, how their leadership development influences them, and how their leadership influences others.

\section{Study context}

The context for this study is one city's efforts to build neighborhood capacity to support children's learning and healthy development. Ready for K sought to achieve its goal, in part, by engaging parents as neighborhood leaders. This paper focuses specifically on the parent leadership component of Ready for $\mathrm{K}$.

Ready for $\mathrm{K}$ focused on five under-served neighborhoods with diverse, large populations of young children likely to be affected by the achievement gap. Poverty rates of children birth through five living in these neighborhoods ranged from approximately 
$30 \%$ to $60 \%$ of all young children (Friedman et al. 2016). The majority of families engaged by Ready for K was born outside the U.S., self-identified as members of a racial minority group, and spoke a language other than or in addition to English. One organization in each neighborhood, referred to as the lead agency, served as the backbone support for Ready for $\mathrm{K}$, and provided overall leadership and management of its implementation. Each lead agency identified a high-level administrator to take on this role, which included coordinating the hiring of the Parent Leaders in their neighborhood. The lead agency also established a Neighborhood Advisory Council made up of parent leaders, partnering agencies and businesses, and other local stakeholders. For example, some of these councils included representatives from local libraries, early childhood programs, community health centers, anti-poverty non-profit organizations, and early intervention programs. These councils met regularly to build a coordinated neighborhood network of resources and supports for school readiness.

Ready for $\mathrm{K}$ recruited neighborhood parents to work as leaders within their community networks to reach under-resourced families through a peer-to-peer model, which emphasized connecting families to school readiness-related activities and resources. Parent Leaders, whose demographics were representative of the families living in these neighborhoods, were recruited to engage families who were not receiving services. Notably, these families may not have been reached through traditional channels due to service access barriers such as language, cultural beliefs, and/or socioeconomic status. Each Parent Leader worked with a supervisor or multiple supervisors in their neighborhood. Ready for $\mathrm{K}$ included a developmental screening initiative, which recruited and trained many of the Parent Leaders to conduct the Ages and Stages Questionnaire (ASQ) screening with families (Squires et al. 1997; Squires and Bricker 2009). To develop and support the ASQ screening component, Parent Leaders participated in leadership training, training on how to administer the ASQ and post-screening referral protocols, and were shadowed by an experienced screener prior to conducting screenings on their own; they also received stipends as payment for their work and supervisory support, attended workshops on early childhood development, and participated in ongoing peerto-peer learning and support. They were organized into teams based on the neighborhood they served.

The reach of the Parent Leaders' work in these neighborhoods was substantial. Over a 4-year period, they engaged approximately 4156 families, which included 6403 adults and 6426 children (Friedman et al. 2016).

\section{Research methods}

This study addresses the following research questions:

1. What strategies did Parent Leaders use in their efforts to engage families?

2. How did parent leadership influence families, neighborhoods, and the Parent Leaders themselves?

To answer these questions, this study used a rigorous, qualitative single case study design (Yin 2014). Case studies provide rich and contextually situated data that can be used to inform and improve practice and policy, and are "the preferred method for 
Table 1 Parent leader data

\begin{tabular}{lll}
\hline Source of data & Timing of data collection & $\begin{array}{l}\text { Total number } \\
\text { of individual } \\
\text { participants }\end{array}$ \\
\hline Focus group & Group \#1 (1st year) & 14 \\
& Group \#2 (3rd year) & 5 \\
& Group \#3 (3rd year) & 7 \\
Individual interviews & 3rd year & 10 \\
Observation of parent leadership event & 3rd year & $3^{\text {a }}$
\end{tabular}

All three ${ }^{a}$ participants who were observed at the leadership event also participated in either a focus group or an individual interview during the 3rd year. We do not know who participated in the 1 st-year focus group, so there may be additional participants who participated several times that are unable to be reported here

Table 2 Additional sources of data

\begin{tabular}{lll}
\hline Participant type & Source of data & $\begin{array}{l}\text { Number } \\
\text { of participants/ } \\
\text { groups }\end{array}$ \\
\hline Neighborhood Lead Agents & & 5 neighborhoods \\
Neighborhood Advisory Councils & Interview \#1 (1st year) & 2 neighborhoods \\
& Interview \#2 (3rd year) & 3 neighborhoods \\
Families in neighborhoods & Focus groups (2nd year) & 4 neighborhoods \\
& Focus groups (3rd year) & 16 \\
\hline
\end{tabular}

a The participants in this table may have participated in more than one meeting/interview/focus group. A limitation of this study was that neighborhood advisory council meeting data were transcribed without names or identifying information

studying interventions or innovations" (Toma 2006, p. 408). The use of case study methodology made it possible to examine and incorporate multiple sources of data about this innovative approach to engaging parents as leaders. These multiple sources of data, collected across 3 years, are represented in Tables 1 and 2. Informed consent was obtained from study participants, in accordance with the study's Institutional Review Board (IRB) approval. The study authors were hired by Ready for K to serve as the external evaluation team for this initiative.

\section{Sources of data}

\section{Parent Leaders}

A total of forty Parent Leaders were consistently and actively engaged with Ready for K between 2011 and 2014, and these were the parents invited to participate in the study. Twenty-nine of these forty Parent Leaders (73\%) agreed to participate in the study. We do not have additional information about the eleven Parent Leaders who did not respond to the invitation to participate in this study, and thus are not included. Of the Parent Leaders $(N=29)$ who elected to participate, they were primarily mothers, immigrants, and spoke the following languages: Spanish, Portuguese, Mandarin, Hebrew, Vietnamese, Cape Verdean Creole, and Arabic. They were diverse racially and ethnically, with $37.9 \%$ identifying as Hispanic/Latina, 17.2\% identifying as Black/African American, 13.8\% identifying as Asian, 3.4\% identifying as White, 8.7\% identifying as Other, and $20.7 \%$ not reporting race or identity (see Table 3 ). 
Table 3 Demographic information of parent leader study participants $(N=29)$

\begin{tabular}{lc}
\hline Variable & $\boldsymbol{N}(\%)$ \\
\hline Race/ethnicity & $11(37.9)$ \\
Hispanic/Latina & $5(17.2)$ \\
Black/African American & $4(13.8)$ \\
Asian & $1(3.4)$ \\
White & $2(6.9)$ \\
Other & $6(20.7)$ \\
Not reported & \\
Languages spoken & $12(41.4)$ \\
Spanish & $3(10.3)$ \\
Vietnamese & $1(3.4)$ \\
Hebrew & $3(10.3)$ \\
Portuguese & $1(3.4)$ \\
Mandarin & $2(6.9)$ \\
Cape Verdean & $4(13.8)$ \\
English only & $3(10.3)$ \\
Not reported & \\
\hline
\end{tabular}

Table 1 presents the data collected from the Parent Leader study participants. In the 1st year, all of the Parent Leaders were invited to participate in a focus group conducted by the first author. In the 3rd year, the Parent Leaders requested the option to participate either in a focus group or in an individual interview. Therefore, in the 3rd year, the second author conducted two Parent Leader focus groups. Some Parent Leaders from the 1st year focus group also participated in the 3rd year data collection, along with new Parent Leaders who had joined after the 1st year. The transcript from the 1st year focus group did not identify individuals and therefore, it is not possible for us to determine which parent leaders participated in both the 1st- and 3rd-year focus groups. Semi-structured qualitative individual interviews were conducted during the 3rd year in a variety of settings (cafes/restaurants, parks/ playgrounds, community based organizations) or via phone, based on the availability and convenience of the participant. The individual interviews ranged from 25 to $60 \mathrm{~min}$. The focus groups lasted $90 \mathrm{~min}$, were semi-structured, and utilized a set of questions in different domains to understand the responsibilities, experiences, development, and challenges of becoming a Parent Leader. Topics of the interviews and focus groups included outreach and engagement strategies and experiences, experiences as a Parent Leader, leadership development, and ASQ screening. Lastly, in the fall of the 3rd year, the second author conducted an observation of three of the Parent Leaders speaking at and facilitating components of a city-wide Ready for $\mathrm{K}$ conference. This observation was more informal in nature, with the observation guide focused on domains of leadership, how their parent leadership led to present work opportunities, the roles they took on in the conference if any (e.g., presenting, leading small group discussions), and how others engaged with them at the conference (e.g., as a parent only vs. as a professional). 


\section{Neighborhood lead agents}

The third and fourth authors conducted semi-structured qualitative interviews with all five neighborhood lead agents who oversaw and managed Ready for K. These included questions about lead agents' experience with and perceptions of the parent leadership efforts. Neighborhood lead agents were interviewed during the 1st and 3rd years of the initiative and questions were revised to capture changes throughout the involvement. Five lead agencies participated in the first round of interviews, and two participated again in the second round of interviews conducted in the 3rd year.

\section{Neighborhood advisory councils}

The third and fourth authors conducted semi-structured qualitative focus groups with each of the five neighborhood school readiness advisory councils that included questions about members' experience with and perceptions of the parent leadership efforts. Each focus group lasted approximately 60-90 min and took place at a Ready for K Neighborhood Advisory Council meeting which was attended by a variety of individuals from community organizations such as child care, human services, and health centers; and the Ready for K leadership. Parent Leaders were also part of these advisory councils, but were not identified individually in this data collection. The focus group protocols contained different questions each year to capture the changes happening within each neighborhood. For instance, in the final year, participants were asked "What changes or growth you have seen throughout the initiative?" as well as "What have you accomplished that you are proud of?" and "What have been your challenges to [collaborative] work?"

\section{Families}

The final data collection component was individual interviews with families who were engaged by Parent Leaders to connect with school readiness resources and screenings. Six graduate research assistants conducted these interviews, assisted by two undergraduate students who served as secondary interviewers. They conducted a total of 16 interviews with families during the 3rd year. Interviews lasted from 40 to $60 \mathrm{~min}$ and were conducted in the families' preferred language by an interviewer fluent in that language, which included: English, Vietnamese, and Spanish. Interviews were primarily conducted in person, taking place in the interviewee's home, with one interview conducted via phone. Interview topics included experience with the ASQ screening for their child, participation in Ready for K activities, experience with Parent Leader(s), ideas about school readiness, changes in parenting style, noticeable changes in child or children, community participation and neighborhood changes. Interviews were translated and transcribed by the graduate student interviewers who were fluent in these languages. Participants were provided with a \$25 gift card.

\section{Data analysis}

The second author entered these data into ATLAS.ti software, and conducted qualitative analysis (Muhr 2004). She analyzed data through qualitative coding procedures, first using a priori codes drawn from the data collection protocol and the literature on 
parent leadership, for example, social networks, friendship, confidence, and training (Miles et al. 2014). She and the first author developed detailed code definitions, and the second author used these definitions to guide ongoing coding to ensure reliability in the use of the codes (Miles et al. 2014). Then, through an inductive thematic coding process, she identified empirically grounded emergent codes, such as boundaries, compensation, increased access to services, being viewed as a leader, shifting attitudes about parent leadership potential, and professionalism. The second author checked these codes against the data, refined and defined with a detailed code definition, reviewed them with the first author, and re-checked (Miles et al. 2014). Given the limited existing research on parent leadership in the urban school readiness context, this inductive approach was essential to enable themes to emerge from the data and deepen the scholarly understanding of parent leadership in this specific context. The data from the multiple sources were compared across sources, referred to as triangulation, to increase validity (Stake 1988; Yin 2014).

The analysis focused on identifying themes from the data about what Parent Leaders did to engage families, as well as study participants' perceptions about how parent leadership influenced the Parent Leaders and others in their neighborhoods. Eleven themes emerged from the analysis. We defined something as a theme when it (1) appeared across two or more different sources of data (e.g., from both family and Parent Leader interviews) or (2) appeared for a majority of respondents within a single source of data and we did not find counter-evidence from other data sources (this occurred in two instances with data from Parent Leaders). The second definition was included because some aspects of the second research question, which addressed facilitators and barriers to parents' development as leaders, relied primarily on the data from the Parent Leaders.

\section{Results}

The analysis showed that Parent Leaders used several highly relational strategies to engage families, and that their leadership influenced families, their neighborhoods, as well as their own identities and experiences as leaders. Table 4 presents each of the research questions alongside the themes that emerged in our analysis, each of which is described more fully below.

Table 4 Results themes

\begin{tabular}{ll}
\hline Research questions & Themes \\
\hline What strategies did parent leaders use? & $\begin{array}{l}\text { Relationship-based outreach and engagement } \\
\text { Communication in a shared language }\end{array}$ \\
& Engaging neighborhood parents as new leaders \\
How did parent leadership influence families? & Social connection \\
How did parent leadership influence neighborhoods? & Children's learning \\
How did parent leadership influence parent leaders them- & A "new norm" about parents as leaders \\
selves? & Developing leadership identities \\
& Confidence \\
& Making a difference \\
& Learned concrete skills \\
& Navigating boundaries
\end{tabular}




\section{Parent Leader strategies}

The first research question asked what Parent Leaders did as leaders to engage families. The results point to three primary strategies these leaders used: building informal relationships with families, communicating in parents' own language, and engaging neighborhood parents as potential new leaders.

\section{Relationship-based outreach and engagement}

Parent Leaders conducted their outreach and engagement activities with families using culturally responsive and relationship-based strategies. The majority of Parent Leaders stated that their preferred outreach strategy was word of mouth in the dayto-day context of life in their neighborhoods. Parent Leaders found that talking with families at community events, parks and playgrounds, neighborhood businesses, and schools were ideal places to reach and engage parents. In these settings, Parent Leaders were able to provide face-to-face reminders about events and build relationships with families, increasing feelings of comfort about attending events. Reaching out to family members, neighbors and friends in their community was typically the first step, and then they asked involved parents to pass the word along to their friends. Parent Leaders who spoke the same language, and had similar cultural values, described their efforts to build trust with families and increase their comfort about attending early learning activities and events. On this foundation of trust, they connected families to local resources, focusing on families who were less comfortable speaking English or talking with providers from different cultural backgrounds. Many Parent Leaders found that sharing their personal story or journey was a particularly effective way to build trust and engage families. As one Parent Leader explained,

I tell them my story first so they can feel comfortable with me. I just tell them 'I've been there.' (Parent Leader 28)

Parent Leaders described learning through experience that families were more likely to try new parenting strategies, such as reading aloud to a child, after seeing Parent Leaders using these strategies effectively with their own children. Due to their membership in the community, Parent Leaders were able to share information in informal ways, such as telling families about a strategy they found helpful while at the park with their children. This was another way that Parent Leaders increased the access of families in the community to child development information. As one parent explained in a family interview:

My family uses the playgroups a lot and that's just something that he [child] has been getting a lot from, like the social interaction and learning new skills. It's good for parents as well, to be able to have play groups. [I] learn a certain tip or get some input and I'll try to practice that. I watched another kid who was throwing something. [The Parent Leader] said 'here's a ball, you can throw a ball', I realized that I need to immediately ... redirect and go do something else. Now I'll do that, scan the room to find the ball and replace it with a new activity. I know it's like a very common thing, but that was actually the first time I heard it, when the Parent Leader was with my group. 
As Parent Leaders worked to connect new families to playgroups, events, and resources, they strongly relied on relationships as a tool for retention and sustaining engagement. Building ongoing relationships with families was a strategy Parent Leaders developed over time with families. One Parent Leader summed this up by saying that "eventually becoming friends" with the parents is part of the job. Parent Leaders found that establishing a friendship with a parent in the community increased the likelihood that parents would reach out with questions or seek help related to child development as well as personal challenges. "[If you] friend with them as person, after that you can like, get them to come to our event or to whatever program you have" (Parent Leader 13). It quickly became the norm to share personal cell phone numbers, which made Parent Leaders more accessible, as "everyone exchanges phone numbers" to make plans to attend neighborhood events together. Parent Leaders appeared to connect with participants on a deeper level than a typical professional might, as they took the time to create "trustful relationships" with families not only as a leader, but as a peer or friend (Parent Leader 2). Parent Leaders expressed caring about the families they served, as evidenced by their provision of individualized support, attending events with parents in the community, and allowing extra time on screening visits to spend time with the parents.

Findings from the family interviews and neighborhood-level data sources provide additional sources of evidence supporting this theme of a highly relational and culturally responsive approach. For example, one parent in a family interview reported, "even after the [child development] screening we still see her [Parent Leader], we became friends and she was the connection with [Ready for $\mathrm{K}$ ] and all the rest of the programs that we are participating in". Neighborhood organizations reported that the parent leadership program had positively impacted their capacity to engage families who they considered hard to reach. They described how families tend to have greater trust and acceptance of Parent Leaders from the same cultures. By recruiting Parent Leaders with diverse cultural backgrounds, more families who were traditionally hard to reach became involved in programming, and created "circles of support" for families as described by one partnering agency leader. The use of parent leadership increased the diversity of involved families, thus connecting providers to communities and families from cultural backgrounds who were previously isolated from available services.

\section{Communicated in a shared language}

Communication in a shared language was a central aspect of the approach developed by Parent Leaders, sharing information, parenting strategies and facilitating the connection to events and resources. Both the style and the specific language of communication between Parent Leaders and families appeared to be important to successful engagement. Parent Leaders were more likely to communicate with families in a manner that was free of professional jargon and status hierarchies. One Parent Leader viewed her role as translational, bringing "research from books (and) from scholars to (the) people's language" (Parent Leader 5). When providing developmental screening results to families, Parent Leaders spoke about the importance of walking the families through the ASQ results, in their native language to ensure understanding. They spoke about the importance of reassuring the parents and providing information about the child's strengths, weaknesses, and specific strategies and resources available as needed. These 
approaches may have eliminated power differentials that would have been present when working with a provider, thus making parents more comfortable and receptive to the information. The importance of language was a theme in the family interviews, as reflected in this quote by a parent who shared her experience of asking for advice following her child's ASQ screening,

When I knew the result [of ASQ] I knew what my disadvantages were, thus I asked. I seek advice from them [the Parent Leader] [She] helped me a lot, gave me toys and tools to teach my kid...they showed me at which month she had to know how to do certain things. They guided me a lot. Even though I am 33 years old now, I have to admit I barely know much about educating kids. I just followed my instinct, but my knowledge is still limited.

In addition to reducing language barriers, Parent Leaders were also able to use their cultural membership to communicate with parents in ways that they understood, and were more likely to be receptive to, as well as increase motivation of the parents by understanding cultural beliefs and traditions. Being from the same cultural background appeared to increase comfort with families and build trust. As one family member described in a family interview,

Those [Parent Leaders] are so nice, so great. Like the reading activities, they often remind me to come to them. They call or text me in advance to remind me of the dates. Those Vietnamese ladies [Parent Leaders]...They keep Vietnamese traditions. Because we're all Vietnamese in the group, we got to keep the traditions. This past Mid-Autumn Festival, the kids all wore Ao Dai [A Vietnamese national garment]. They looked so cute, the festival was so much fun.

\section{Engaging neighborhood parents as new leaders}

Another strategy Parent Leaders used was to not only connect families to school readiness resources, but also seek out parents who might want to become Parent Leaders themselves. In this way, Parent Leaders identified and engaged potential new leaders. Many Parent Leaders got their start through their own involvement in Ready for K parenting activities, and were recruited for leadership by Ready for K organizers. Parent Leaders recognized commitment or qualities of parents in the community, seeing them as strong candidates for future Parent Leader positions, and saw their work as part of a cycle for empowering parents in their communities. Parents in the community were empowered to lead playgroups, volunteer at events, participate in Neighborhood Advisory Council meetings, and eventually become Parent Leaders. As stated by one neighborhood leader, "either they are [a] Parent Leader or they become leaders" [referring to engagement of parents in the community]. In one instance, Parent Leaders took initiative to teach each other new skills that would be valuable in future work settings, such as learning new languages or learning how to set up an email. Parent Leaders viewed part of their roles as recognizing skills in parents, to "lead and inspire others in the community" (Parent Leader 10), exposing parents to the work they are already doing with their children, and providing them with support so they are able to lead their own workshop or playgroup, as we observed in the Parent Leader-led training. The mindset of Parent 
Leaders was very often one of "paying it forward," as stated by one Parent Leader (Parent Leader 5), referring to the practice of extending kindness and good deeds to someone else after you have been the recipient of the kindness of others. As one Parent Leader stated in the first focus group, "Participating in this group as a parent, having opportunities that empowered me to empower other parents in this community has been just such beautiful work. I call it a job done with the heart."

\section{Influence of parent leadership on families}

There were two key impacts of Parent Leadership reported for neighborhood families: an increase in social connection and children's learning.

\section{Social connection}

Families reported meeting and connecting with new people, increased opportunities to talk with other parents, and experiencing an increased sense of social connection in their neighborhood, as a result of Ready for K involvement. Several families described feeling isolated until they were engaged by Parent Leaders and began attending events and participating in family activities where they formed connections. Involvement in Ready for $\mathrm{K}$ increased feelings of connectedness and broadened participants' social network. One family interview participant explained,

The truth is that we have been engaging because we don't want to feel alone or isolated; we don't know anything or anybody and this has helped us, it has connected us, from one place to the other one, from one person to the other one and then that's how we got to know this program that has helped us a lot.

Parent Leaders reported observing increased engagement among families in their communities as a result of their outreach efforts with Ready for K. As shared by one Parent Leader,

Every afternoon when you go to the library ...you know different moms with different kids, it's the place to be and that's come out of I would say [Ready for K] because everyone wasn't as united. Parent engagement was a tough idea (Parent Leader 5).

Increased connection was particularly evident in traditionally hard to reach populations, such as families who recently immigrated to the U.S., which was reported by parent leaders and neighborhood lead agents. As stated by one lead agent,

I can see [families] participating in a lot of different things, learning new things, getting to know each other. Isolation, all those barriers we're able to break or at least try to break because of the collaboration.

\section{Children's learning}

Families who were engaged also reported positive impacts of Ready for $\mathrm{K}$ for their children. Almost all families interviewed described increased school readiness in their children in areas such as fine motor skills, play, communication, early literacy, self-regulation, social skills and openness to new experiences. They attributed these gains to the 
playgroups and literacy activities, and to the structure, consistency, and peer interactions offered by these activities.

\section{Influence on neighborhoods}

Moving beyond their influence directly with families, Parent Leaders influenced changes in attitudes of professionals in their neighborhood about parent leadership.

\section{A "new norm" about parents as leaders}

Parent Leaders came to be viewed with great respect, and were increasingly involved in opportunities such as the Neighborhood Advisory Council meetings. They were given the opportunity to share their voice and experiences with the organizations with which they worked and from which they potentially received resources. Many of the neighborhood organizational partners described a new awareness about the contributions Parent Leaders can make, resulting in a shift in norms in their organization. One neighborhood lead agent explained,

The new norm is 'ask the Parent (leaders).' Three or four years ago, I would be asking our [other] agencies. Now, they even call and ask us....can you ask the Parent Leaders about this or that?'.. that's what the talk is all about. We're looking for the parent's perspective. I think that's a huge shift, because it wasn't that way four years ago. Of course, we could always do surveys for parents on what they wanted....but nothing with actual parent representatives...

In another example, one public agency previously hired college student interns, but as a result of the parent leadership successes, they began hiring parents as interns and family engagement specialists.

When asked what was most promising or effective based on what was learned doing this work, one neighborhood agency leader stated,

I would be putting more time and resources into the parent leadership side of it. I think that's where the real potential gains are. We've had parents go on to actually lead playgroups themselves. Or parents who become parent-child home visitors. One of the best visitors that we've had who is serving a large number of families is Maria [pseudonym]. She is now working for the Head Start program. She got a full-time job there. She still does the parent [leadership] work. So I think the parent [leadership] program is focusing on particular neighborhoods in engaging families who we're not likely to reach through other methods.

There was widespread agreement that attitudes about parent leadership have been transformed by increasing recognition of Parent Leaders in the community. According to Ready for K lead agents, the role of parents has become "really big" and has changed the focus of family engagement. For example, the influence of Parent Leaders led to structural changes to further promote parent involvement. These included changing meetings to a time that was more convenient for parents, to promote their involvement. As one neighborhood lead agent explained,

We started looking at parents more as leaders rather than the people that we serve and that really changed the tone of the conversation because we saw them as people 
with their own expertise and we consulted with them. So it was very fruitful because

they knew exactly how to run things - what things work and what did not work.

Parent Leaders came to be viewed as people who can make a difference in the community. These neighborhood lead agents found that the Parent Leaders were strongly successful due to their determination and the initiative they took within their community, as illustrated by one neighborhood agency leaders who stated, "they were leaders because they learned how to be leaders and to see the needs of the community and 'jump to it."

\section{Influence on Parent Leaders}

The analysis also revealed that becoming a leader influenced the Parent Leaders themselves in five key ways.

\section{Developing leadership identities}

As Parent Leaders came to be recognized and valued as leaders in the community, there was a shift in how they saw themselves. We described how community members came to see parents differently as a result of their leadership development, and we found that the Parent Leaders also came to see themselves differently, newly identifying as a leader. Parent Leaders developed their own individual and collective identities as leaders, recognized their capacity to make a difference, and gained a sense of belonging to a collective force for positive change.

\section{Confidence}

Many Parent Leaders spoke about the experience and process of finding their voice as a leader. They described feeling more confident, more likely to speak up, and more comfortable speaking English. Many noted that they were previously shy or became less shy through their experiences. "I was very shy to talk in public... I feel more confident about that-talking with people and now I run workshops" (Parent Leader 6). Similarly, another Parent Leader reported "Before, I never confident. I cannot, even with Vietnamese parents, I cannot confident to communicate with them but now I can communicate with everyone, not only Vietnamese" (Parent Leader 12). Three Parent Leaders were observed speaking on a panel at a leadership conference, confidently sharing their experiences and leading attendees in activities focused on their individual areas of expertise. During this observation, a number of attendees approached these Parent Leaders to exchange contact information and indicated they hoped to invite them for additional speaking engagements.

\section{Making a difference}

Parent Leaders spoke about the impact they believed they were making on their community as a whole, and the rewarding feelings that stemmed from this. Parent Leaders spoke about feeling happy and proud to have the ability to help others, as well as feeling good about the difference they were making in the lives of those they reached, knowing that they were "being part of a driving force for a good change in people's lives" (Parent Leader 5). Several spoke about a responsibility to families that came with their new 
recognition as a Parent Leader, with parents in the community increasingly reaching out with questions surrounding access to resources. As one Parent Leader explained,

Now when I see people I wanna advise them like if I know information- ok I'm gonna tell you what's going on and then I'm gonna call you back - I feel this responsibility ... you feel like the community needs you (Parent Leader 7).

Many Parent Leaders reported increased feelings of belongingness as a result of their leadership experience. This consisted of an expanded support network, building of friendships and relationships, and greater connection with the community. For example,

In a way it's connected me a little bit more to the community where I live...I wasn't very - we came from Brazil three years ago and I'm very connected to [that] community around here...but I wasn't very connected to the people in my neighborhood (Parent Leader 2).

In addition, one participant highlighted the importance of her title as Parent Leader that contributed to her feelings of belongingness. She explained,

And there's this word for this belonging feeling where [I feel] I am important you know - I don't know the word. Not entitlement. Like a recognition, you have a status (Parent Leader 5).

All Parent Leaders interviewed, as well as those who participated in focus groups, spoke about learning from their fellow Parent Leaders as a major part of their experience, reinforcing the sense of belonging to a supportive learning community. Parent Leaders worked together, helped each other out with challenges and difficult situations, shared resources and information at their meetings and served as a general support network. Those with the most experience provided support to newer Parent Leaders, orienting each other to their new roles by modeling skills and working on projects with new members.

\section{Learned concrete skills}

Parent Leaders and neighborhood respondents attested to the Parent Leaders' acquisition of new professional skills. As a result of these new skills, many Parent Leaders accessed new professional employment opportunities, often as a result of contacts they made while collaborating with partnering community agencies. Some of the interpersonal skills acquired included how to engage in self-advocacy, how to talk to families, how to make connections with others, being flexible, and developing greater patience and empathy. Many Parent Leaders shared that their involvement shaped their future professional goals and the career they hoped to pursue. The experiences and skills acquired helped Parent Leaders realize their ability to succeed in a field related to this work, which in many cases led to a change in career. As reported by one neighborhood lead agent, a Parent Leader who came to her organization to receive services is now employed by that agency, and "Her role is to mobilize other parents to be their children's first and most important teacher and she does that". This appeared to be particularly salient to individuals who immigrated to the United States, finding a new sense of purpose and gaining work experience in the U.S. These findings were supported by data 
from multiple sources, including Parent Leaders as well as neighborhood partners. For instance, in one neighborhood, the practical experience working with children bolstered a Parent Leader's resume enabling her to apply for a new professional work opportunity,

So in order to be able to apply for this paraprofessional training program we'd need to have a kind of background of working with kids so [Ready for K] help us to put on the resume and they pick us and it's great and I know it's because we have all these background of working with families from the community (Parent Leader 21).

\section{Negotiating professional boundaries}

This study also surfaced one theme that reflected a challenge Parent Leaders encountered in their work. Some Parent Leaders struggled with defining professional roles and boundaries in their work with parents. Parent leaders came to be viewed as role models and advocates in their communities. With this recognition, neighborhood parents approached some of the Parent Leaders for information and advice about child development, parenting, family crises, and interpersonal violence. Parent leaders grappled with how to balance being "real" with families and being professional at the same time. What are the boundaries of the role? Under what circumstances might they do "for" someone, rather than empowering parents to do something for themselves, or vice versa? Determining what kinds of personal information sharing and support was appropriate was largely unclear and not specified by Ready for K. Parent leaders had to determine how to set boundaries with families based on their own comfort level, but inevitably ended up fulfilling many complex needs and donating their time to help. One Parent Leader described this challenge,

Sometimes families they see you as a social worker...it's not easy to just take this huge responsibility... you just wanna but some families are in really big needs and they see you as a leader and they just come to you and say help me out please and you're like oh my god what are you gonna do you know? (Parent Leader 21)

Another Parent Leader explained a similar challenge, saying

When we sign up a family we become their friend they can call at any time of the day like they call us in the weekend and ask what's happening during this weekend? What programs provided? (Parent Leader 2)

Some of the Parent Leaders spoke about feeling overwhelmed attempting to manage the multiple roles they played in the lives of families, such as the balance of being a friend and connecting them to resources, while hoping to empower parents to help themselves.

\section{Discussion}

This study contributes to an increased understanding about what parent leadership is and how it might matter in urban, predominantly immigrant communities such as those that were the context for this study. Like prior research on parent leadership development, we found that developing a leadership identity was a part of a transformational process of individual and collective empowerment that influenced how others viewed 
parent leadership (Cunningham et al. 2012; Ely et al. 2011; Walker 2009). Parent Leaders engaged large numbers of families to participate in school readiness activities and did so in ways that built trust with the families they engaged. They employed many of the community organizing strategies identified by Cunningham et al. (2012), such as relationship-based outreach and recruiting new parent leaders in their neighborhoods. Families described the powerful experiences they had with Parent Leaders that supported them and their children. Families reported benefits for themselves of greater social connections and benefits for their children's learning as a result of participation in community school readiness supports. When families described the impact of Parent Leaders, they often described the level of trust, familiarity, and cultural connection they experienced in their interactions with Parent Leaders. Some described the Parent Leaders as a peer or a role model for them as a parent. This lack of a professional distance between the Parent Leader and families may have fostered greater engagement of families, but it also created challenges for some of the Parent Leaders when it came to setting boundaries between their personal life and their role as a Parent Leader in their neighborhood.

We also found that the leadership development of parents might act to reduce professionals' deficit-based attitudes about parents, as did Geller et al. (2015) in their study of parents and teachers. Given our finding that parent leadership influenced professionals' attitudes, an area for further research could be to examine how this kind of parent leadership development initiative might influence early childhood educators' attitudes about parents. Prior research highlights differential power relations between parents and professionals as a barrier to parent engagement and parent leadership (Vlasov and Hujala 2017; Douglass 2011). This study showed how parent leadership influenced a shift in that balance of power. Exposure to parent leadership prompted some community leaders to adopt new attitudes about parents as people who can make a difference rather than as service recipients, offering an important insight about this pathway of influence of parent leadership development.

Parent leadership influenced not only how others saw these parents in their neighborhoods, but also how they saw themselves and their opportunities for personal and professional growth. Parent Leaders drew upon their unique strengths as well as their cultural and linguistic capacities. They learned new professional skills in this process. Prior research has shown that parent leadership development can result in new skills, increased confidence, and new employment opportunities (Ball 2008; Bray and Kenney 2014; Cunningham et al. 2012) and we found evidence of this in our study. As parents developed their identity as leaders, they gained confidence and an enhanced sense of purpose about their leadership. They gained knowledge and skills related to parenting, community engagement, child development, and developmental screening, and some chose to take new jobs working in early childhood and/or family support professional positions.

Several recommendations for parent leadership have emerged based on the results of this study. First, important benefits may come from developing parent leadership pathways and expanding parent voice in community school readiness and early childhood initiatives. Many lessons were learned from this study about how to develop parent leadership that can inform efforts to implement a similar parent leadership pathway. Parent Leaders had distinct and authentic roles in recruiting and conducting screening 
with families, and they became part of a cohort of parent leaders that provided a sense of belonging and mutual support. These may be important aspects of the successes of this initiative when it came to influencing families and the neighborhoods in which they worked. Future research can test this finding in other contexts to further develop the evidence based about parent leadership in early childhood.

Another recommendation is about planning for sustainability. Because Ready for $\mathrm{K}$ was funded through philanthropic grant funding, when the funding came close to an end many participants, including Parent Leaders became concerned about its sustainability. They reported that while the Parent Leadership efforts were viewed as one of the most highly successful components of Ready for K, it was in jeopardy for the future without ongoing funding. It is important to consider how more sustainable funding might be secured to support parent leadership efforts, and to evaluate this and its impact. Lastly, the parent leadership strategy highlights the importance of addressing the boundaries of the parent leadership role from the beginning. Defining role boundaries should include the co-creation of guidelines to support effective interpersonal relationships between parent leaders and the families with whom they work, and the family support literature offers guidance about this (Bruner 1998). Other supportive strategies may include reflective orientation, supervision and mentoring for parent leaders. Parent leadership may be a promising practice in urban school readiness and early education efforts, and should be a focus of new research, policy, and practice innovations.

\section{Conclusion}

This paper contributes to a small but important and timely literature on parent leadership for early learning and school readiness. Strong, linguistic and culturally diverse cadres of Parent Leaders were considered central to Ready for K's successes in reaching and engaging under-resourced families. While most school readiness efforts to date have focused on the school-based professional approach to enhancing children's academic and social preparation for school, Ready for K took a more comprehensive approach, both in engaging and supporting parents, and also by promoting strong parent leadership. The importance of an intentional emphasis on diversity, cultural competency and the empowerment of families is noted in this and other studies, and is an area that would benefit from continued attention in research and practice. Parent leadership holds transformative potential, and demands a new era of research and innovation.

Acknowledgements

Not applicable.

Authors' contributions

ALD made substantial contributions to conception and design, data analysis, and was a major contributor in writing the manuscript. MRM was involved in data collection, data analysis, writing and revising the manuscript. MC, DHF and AC were involved in data collection/analysis and MC and DHF were involved in manuscript revisions. All authors read and approved final manuscript.

Funding

This study was conducted as a program evaluation funded by Thrive in Five, Boston, MA.

Availability of data and materials

The datasets generated and analyzed during the current study are not publicly available due to the way the study was funded and conducted, but are available from the corresponding author on reasonable request.

Competing interests

The authors declare that they have no competing interests. 


\section{Author details}

${ }^{1}$ College of Education and Human Development, University of Massachusetts Boston, 100 Morrissey Blvd., Boston, MA

02125, USA. ${ }^{2}$ Center for Social Policy, University of Massachusetts Boston, 100 Morrissey Blvd., Boston, MA 02125, USA.

3 Psychology Department, University of Massachusetts Boston, 100 Morrissey Blvd, Boston, MA 02125, USA.

Received: 22 October 2018 Accepted: 7 June 2019

Published online: 17 June 2019

\section{References}

Ball, C. (2008). Enhancing community capacity to engage and involve immigrant and refugee families: A model for inclusive collaboration. Families First Edmonton.

Blitz, L. V., \& Greene, M. P. (2014). Supporting her rise to power: Developing multicultural women-affirming leadership. Training and Development in Human Services. The Journal of the National Staff Development and Training Association, $8(1), 35-49$.

Bolívar, J. M., \& Chrispeels, J. H. (2011). Enhancing parent leadership through building social and intellectual capital. American Educational Research Journal, 48(1), 4-38. https://doi.org/10.3102/0002831210366466.

Bray, P. M., \& Kenney, E. M. (2014). Parent leaders taking the lead: Capacity building and co-constructed relevance in community-engaged research. Journal of Public Scholarship in Higher Education, 4, 93-109.

Bray, P. M., Pedro, J., Kenney, E. M., \& Gannotti, M. (2014). Collaborative action inquiry: A tool for, and result of, parent learning and leadership. Journal of Community Engagement and Scholarship, 7(1), 3-14. Retrieved from http://jces.ua.edu/ collaborative-action-inquiry-a-tool-for-and-result-of-parent-learning-and-leadership/. Accessed 10 Jan 2018.

Brittain, C. (2014). An example of leadership transfer of learning through the NCWWI Toolkit: Learning and living leadership. Training and Development in Human Services. The Journal of the National StaffDevelopment and Training Association, 8(1), 56-59. Retrieved from http://icpc.aphsa.org/content/dam/NSDTA/PDF/Resources/NDSTA10.27. pdf\#page $=57$. Accessed 10 Jan 2018.

Bruner, C. (1998). Wise counsel: redefining the role of consumers, professionals and community workers in the helping process. Des Moines: National Center for Service Integration, Child and Family Policy Center.

Cunningham, S. D., Kreider, H., \& Ocón, J. (2012). Influence of a parent leadership program on participants'leadership capacity and actions. School Community Journal, 22(1), 111-124. Retrieved from http://www.adi.org/journal/2012ss/ CunninghamKreiderOconSpring2012.pdf. Accessed 10 Jan 2018.

Douglass, A. (2011). Improving family engagement: The organizational context and its influence on partnering with parents in formal child care settings. Early Childhood Research and Practice, 13(2). Retrieved from http://ecrp.uiuc. edu/v13n2/douglass.html. Accessed 10 Jan 2018.

Douglass, A. (2018). Redefining leadership: Lessons from an early education leadership development initiative. Early Childhood Education Journal, 46(4), 387-396.

Douglass, A., \& Klerman, L. (2012). The strengthening families initiative and child care quality improvement: How Strengthening Families influenced change in child care programs in one state. Early Education and Development, 23, 373-392.

Ely, R. J., Ibarra, H., \& Kolb, D. M. (2011). Taking gender into account: Theory and design for women's leadership development programs. Academy of Management Learning \& Education, 10(3), 474-493. https://doi.org/10.5465/ amle_2010.0046.

Friedman, D., Coonan, M., Douglass, A., \& Carter, A. (2016). Boston children thrive in 5: Connecting families, building community, year 4-Summative evaluation brief. Boston: University of Massachusetts Boston.

Geller, J. D., Alcantara, V., Boucher, D., Catone, K., Lopez, R. M., \& Tung, R. (2015). What does it take to form meaningful connections among cultural brokers, parents, and teachers? Lessons from a Federal Grant. Journal of Family Diversity in Education, 1(4), 22-44.

Gutierrez, S. (2013). Parents as agents of change. Family Involvement Network of Educators (FINE) Newsletter, V(3). Retrieved from https://archive.globalfrp.org/publications-resources/browse-our-publications/parents-as-agents-of-change. Accessed 10 Jan 2018.

Hakyemez-Paul, S., Pihlaja, P., \& Silvennoinen, H. (2018). Parental involvement in Finnish day care-What do early childhood educators say? European Early Childhood Education Research Journal, 26(2), 258-273. https://doi. org/10.1080/1350293x.2018.1442042.

Henderson, A., Jacob, B., Kernan-Schloss, A., \& Raimondo, B. (2004). The case for parent leadership. Lexington: Prichard Committee for Academic Excellence.

Hepburn, K. S. (2004). Families as primary partners in their child's development \& school readiness. Annie E. Casey Foundation. Retrieved from http://files.eric.ed.gov/fulltext/ED485897.pdf. Accessed 10 Jan 2018.

Langford, J., \& Weissbourd, B. (1997). New directions for parent leadership in a family-support context. In S. L. Kagan \& B. T. Bowman (Eds.), Leadership in early care and education (pp. 147-153). Washington D.C.: National Association for the Education of Young Children.

Miles, M. B., Huberman, A. M., \& Saldaña, J. (2014). Qualitative data analysis: A methods sourcebook. Thousand Oaks: Sage.

Morrow, G., \& Malin, N. (2004). Parents and professionals working together: Turning the rhetoric into reality. Early Years: Journal of International Research and Development, 24(2), 163-177. https://doi.org/10.1080/0957514032000733019.

Muhr, T. (2004). User's manual for ATLAS.ti 5.0. Berlin: Scientific Software Development.

National Center on Parent, Family and Community Engagement. (2019). Families as advocates and leaders. Boston: Boston Children's Hospital. Retrieved from https://eclkc.ohs.acf.hhs.gov/sites/default/files/pdf/rtp-advocates-leaders.pdf. Accessed 3 Feb 2019. 
OECD. (2012). Starting strong III: A quality toolbox for early childhood education and care. Policy lever 4: Engaging families and communities. Paris: OECD Publishing. Retrieved from http://www.oecd.org/education/school/startingstrongiii-aqual itytoolboxforearlychildhoodeducationandcare.htm. Accessed 3 Feb 2019.

OECD. (2017). Starting strong 2017: Key OECD indicators on early childhood education and care. Paris: OECD Publishing. Retrieved from http://www.oecd.org/education/starting-strong-2017-9789264276116-en.htm. Accessed 3 Feb 2019.

Park, M., \& McHugh, M. (2014). Immigrant parents and early childhood programs: Addressing barriers of literacy, culture, and systems knowledge. National Center on Immigrant Integration Policy, Migration Policy Institute. Retrieved from https ://www.migrationpolicy.org/research/immigrant-parents-early-childhood-programs-barriers. Accessed $10 \mathrm{Jan} 2018$.

Solloway, M., \& Girouard, S. (2004). Voices of change for Connecticut's children: Promoting parent leadership and civic literacy: An evaluation of the Connecticut Commission on Children's Parent Leadership Training Institute. Hartford: Connecticut Commission on Children.

Souto-Manning, M., \& Swick, K. J. (2006). Teachers' beliefs about parent and family involvement: Rethinking our family involvement paradigm. Early Childhood Education Journal, 34(2), 187-193. https://doi.org/10.1007/s1064 3-006-0063-5.

Squires, J., \& Bricker, D. (2009). Ages \& stages Questionnaires ${ }^{\circledR}$ (3rd ed.) Psychtests. https://doi.org/10.1037/t11523-000.

Squires, J., Bricker, D., \& Potter, L. (1997). Revision of a parent-completed developmental screening tool: Ages and stages questionnaires. Journal of Pediatric Psychology, 22(3), 313-328.

Stake, R. E. (1988). Case study methods in educational research: Seeking sweet water. In R. M. Jaeger (Ed.), Complementary methods for research in education. Washington DC: American Educational Research Association.

Swick, K. J. (2001). Service-learning in teacher education: Building learning communities. The Clearing House: A Journal of Educational Strategies, Issues, and Ideas, 74(5), 261-264. https://doi.org/10.1080/00098650109599204.

Toma, J. D. (2006). Approaching rigor in applied qualitative research. In C. F. Conrad \& R. C. Serlin (Eds.), The SAGE handbook for research in education: Engaging ideas and enriching inquiry (pp. 405-424). Thousand Oaks: SAGE Publications.

Toso, B. W., \& Gungor, R. (2012). Parent engagement and parent leadership. In B. H. Wasik (Ed.), Handbook of family literacy (pp. 223-235). New York: Routledge.

U.S. Department of Health and Human Services. (2011). The head start parent, family, and community engagement framework: Promoting family engagement and school readiness from prenatal to age 8. Washington D.C.: Office of Head Start and the National Center on Parent, Family, and Community Engagement. Retrieved from http://www.ohcac.org/ HeadStart/HS_PARENT,_FAMILY,_AND_COMMUNITY_ENGAGEMENT_FRAMEWORK.pdf. Accessed 10 Jan 2018.

Vlasov, J., \& Hujala, E. (2017). Parent-teacher cooperation in early childhood education—Directors' views to changes in the USA, Russia, and Finland. European Early Childhood Education Research Journal, 25(5), 732-746. https://doi. org/10.1080/1350293x.2017.1356536.

Walker, T. D. (2009). Parents as leaders: A transrelational approach to intentional family leadership and poverty intervention. (Doctoral dissertation). Retrieved from PSYCH Info. (UMI number: 3437367).

Yin, R. K. (2014). Case study research design and methods (5th ed.). Thousand Oaks: Sage.

\section{Publisher's Note}

Springer Nature remains neutral with regard to jurisdictional claims in published maps and institutional affiliations.

\section{Submit your manuscript to a SpringerOpen ${ }^{\circ}$ journal and benefit from:}

- Convenient online submission

- Rigorous peer review

- Open access: articles freely available online

- High visibility within the field

- Retaining the copyright to your article

Submit your next manuscript at $\boldsymbol{\Delta}$ springeropen.com 